\title{
Environmental Factors Assisted the Evaluation of Entropy Water Quality Indices With Efficient Machine Learning Technique
}

\section{Jingjing Xia}

Wuhan University of Technology

Jin Zeng ( $\boldsymbol{\sigma}$ zjcrystal@hust.edu.cn )

Huazhong University of Science and Technology https://orcid.org/0000-0002-7058-5804

\section{Research Article}

Keywords: Water quality, Correlation analysis, Machine learning method, Non-linear regression prediction, Non-linear regression classification

Posted Date: December 21st, 2021

DOI: https://doi.org/10.21203/rs.3.rs-1183824/v1

License: (c) (1) This work is licensed under a Creative Commons Attribution 4.0 International License.

Read Full License

Version of Record: A version of this preprint was published at Water Resources Management on April 7th, 2022. See the published version at https://doi.org/10.1007/s11269-022-03126-z. 


\section{Environmental factors assisted the evaluation of}

2 entropy water quality indices with efficient machine

3 learning technique

Jingjing Xia ${ }^{1,2,3}$, Jin Zeng ${ }^{4, *}$

5 1. School of Resources and Environmental Engineering, Wuhan University of

6 Technology, Wuhan, Hubei, 430070, China

7 2. Institute of Environmental Industry of Huangshi, Hubei Polytechnic University,

8 Huangshi, Hubei, 435003, China

9 3. School of Environmental Science and Engineering, Hubei Polytechnic University,

10 Huangshi, Hubei, 435003, China

11 4. School of Cyber Science and Engineering, Huazhong University of Science and

12 Technology, Wuhan, Hubei, 430074, China

Abstract: Water is an indispensable resource for human production and life. The evaluation of water quality by scientific method that provides sufficient support for the regeneration and recycling utilization of water resources. At present, water quality is mainly evaluated by water quality index (WQI) with weighted entropy value, which comprehensively considers the influence of different relevant environmental factors on the water quality. The calculation process is very complicated and time-consuming. In this paper, the method of correlation analysis is used to select the best combination of relevant environmental factors to assist the prediction model. Two typical kinds of machine learning methods are adopted and compared to realize the prediction of 
entropy water quality index (EWQI). After the better framework of prediction model is selected, four different kinds of optimization algorithms are used to optimize the prediction model to realize non-linear regression prediction and classification of water quality. According to the results of evaluation indicators, the framework of SVM is more suitable for realizing the prediction of EWQI. Meanwhile, the optimization algorithm of DE-GWO show great potential to improve the performance of SVM, which can make further contribution to the rational use and protection of water resources.

Keywords: Water quality; Correlation analysis; Machine learning method; Non-linear regression prediction; Non-linear regression classification;

\section{Introduction}

In the past several decades, rapid population growth accompanied by the ascending trend of urbanization, agriculture and industrialization have imposed numerous stresses on the natural systems. The contradiction between growing demands and availability of water has been one of the major constraints on global development, which is even tougher in developing countries(van Vliet et al., 2021; Xiao et al., 2019; Yang et al., 2018; Zahedi et al., 2017). The growing trend of agricultural, domestic and industrial water demands and assumption produced a large amount of wastewater that was discharged directly into the rivers due to the lack of enough sewage collection and treatment systems. Water plays pivotal roles in ecological and human health, economic development and social prosperity; thus, it is an exacting task to prevent and control 
declining water quality in waterbody (Dhanasekarapandian et al., 2016; Wu et al., 2018). Understanding conditions and robust assessment of surface water quality are essential to provide reliable information for decision making and effective management strategies.

Surface water quality evaluation is a highly fundamental and important task for water environment management. Assessing water quality needs plenty of monitoring data of physical, chemical, and biological parameters. Traditional water quality evaluation methods compared each water quality parameter with the existing standard levels and then rank the grade of the overall water quality by the worst one. Water quality categories and the main pollution factors can be determined quickly and intuitively, but it can provide neither continuous and quantitative analysis nor timely early warning. Water quality indices (WQIs) which is a mathematical instrument can integrate and interpret a group of water-monitoring data in a single composite value in a simple and an understandable manner (Nong et al., 2020). WQIs can describe a comprehensive picture of water quality spatially and temporally and make comparative analyses among different rivers, regions or basins. They facilitate the rapid transfer of information about water quality to water resource managers and the general public, guiding decision makers' policies and actions.

WQI was proposed since 1970s and has been widely used to evaluate the water quality around the world (Hou et al., 2016; Kaurish and Younos, 2007), such as the Canadian Water Quality index (CWQI), the British Columbia Water Quality Index (BCWQI), the Florida Stream Water Quality Index (FWQI), and others. The difference 
of water quality indexes is caused by the differences in the characteristics of statistical integration with different sub-indices and WQI calculation equations (Ahsan et al., 2021; Ameen, 2019; Gao et al., 2020; Seifi et al., 2020; Tian et al., 2019; Wu et al., 2020; Xia et al., 2018; Zahedi et al., 2017). Many of them are subjective evaluation technique that largely rely on expert experience and judgment in assigning parameter weights and setting gradation standard, which result in losing the significant information about water quality (Sutadian et al., 2017; Zahedi et al., 2017). In contrast, objective-weighting system can overcome this limitation to achieve the robustness of water quality evaluation, since it depends on monitored indicators and local variations in a dataset without any artificial perception. In this regard, the entropy weight-based water quality index (EWQI) that adopts information entropy to define the disorder or uncertainty in a random process, which can provide more accurate and reliable water quality assessment (Feng et al., 2019; Singha et al., 2021).

WQI calculation is a computationally intensive task that is so complex and requires a lot of time, which affects the decision-making ability of water resources management. In this context, machine learning technique has been increasingly adopted to water quality modelling and evaluations for quick and accurate assessment results (Rajaee et al., 2020). Successful computations of WQI have been achieved using artificial neural network (ANN) and support vector machine (SVM). Sakizadeh optimizes the ANN prediction model by introducing the method of Bayesian regularization, and the accuracy can reach to $95 \%$ (Sakizadeh et al, 2016). Machiwal uses the technology of ANN to assist the groundwater quality evaluation and protection (Machiwal D et al, 
2018). Gupta et al. proposed to use a complex cascaded forward neural network to realize the prediction of WQI (Gupta et al, 2019). ANN-based WQI can achieve high prediction accuracy, while it has higher requirements on the complex network structure and has some weaknesses when datasets are small. SVM is a supervised learning network structure based on radial basis. Its structure is simple and it is more suitable for small sample learning and data-missing environments. Hamzeh et al. use SVM to realize the prediction of WQI, the prediction accuracy is improved, and the time for model training and testing is greatly reduced (Hamzeh 2018). Meanwhile, in order to avoid the local optimal solution of SVM in the model prediction process, Wang optimizes SVM through PSO to achieve WQI prediction (Wang et al, 2017). However, there is still a lack of comparative analysis between ANN and SVM in the field of WQI prediction, and the pros and cons of different SVM-based optimization algorithms are not well explained.

The Pearl River Delta (PRD) is one of the most populated regions with the highest rate of developmental and infrastructural activities in China ( $\mathrm{Li}$ et al., 2019; Nukapothula et al., 2019). It has experienced several decades of extensive development since the reform and opening policy. Many factories were built and large population influx in for jobs and better lives. Thus, much nutrient and pollutants input into rivers and toward the sea, leading to water quality deterioration. Moreover, with backflow of seawater, water pollution is more serious in Pearl River Delta Estuary. Considering the importance of PRD in the new development stage of China, there is an urgent need for effective continuous monitoring of the water quality in this region 
which is useful for its economic and social sustainable development.

In this paper, EWQI is used to evaluate the water quality of PRD, which can avoid the lack of water quality information caused by the empirical weight. Two typical kinds of machine learning method (ANN and SVM) are used to realize the prediction of EWQI. While comparing and analyzing the pros and cons of two typical prediction models, the better machine learning method can be selected. Then, four different intelligent algorithms are adopted to optimize the machine learing method to realize the prediction of EWQI in high accuracy. The content of this paper mainly divided into the follwing parts: Section 2 describes the study area and data collection. Section 3 describes the method. Section 4 makes a comparions of different optimization machine learning method. Section 5 concludes the whole paper.

\section{Study area and data collection}

\subsection{The study area}

The Pearl River system $\left(113^{\circ} \mathrm{E}, 23^{\circ} \mathrm{N}\right)$ originates from the Yunnan-Guizhou Plateau, which flowing through the regions of Guangdong and Guangxi, and finally entering into the South Sea of china via the estuary of the PRD. As the second largest river system in the country, the annual runoff exceeds 349.2 billion cubic meters which is only lower than that of the Yangtze River. The Pearl River system has a total length of 2,320 kilometers, and the entire drainage area is about 440,000 square kilometers.

In order to continuous monitoring the change of the water quality of the Pearl River Estuary (PRE). Multiple water quality monitoring stations have been set in different 
sub-basins, and conducts monthly sampling and systematic evaluation. With a comprehensive consideration of the distribution of the monitoring stations and the completeness of data collection, 5 typical monitoring stations (Lixinsha, Tingjiao Bridge, Xiaohu, Nanheng, Jiaomen) are selected as the source of the research data. The location of PRE and distribution of the monitoring stations as shown in Fig. 1.

\subsection{Data collection}

Nine years (2011-2019) of monthly water quality data were being sampled at five monitoring stations respectively. These data include $\mathrm{COD}, \mathrm{DO}, \mathrm{BOD} 5, \mathrm{NH}_{3}-\mathrm{N}, \mathrm{TN}, \mathrm{TP}$, Petroleum, FC, and the details of water quality as shown in the Table. 1. The descriptive statistics of water quality data as shown in the Table. 2, which mainly include min, max, standard deviation (SD) and so on.

Table. 1 Details of water quality used for calculation and screening

\begin{tabular}{llc}
\hline Abbreviation of Environment Variables & Full Variable Name & Unit \\
\hline COD & Chemical oxygen demand & $\mathrm{mg} / \mathrm{L}$ \\
DO & Dissolved oxygen & $\mathrm{mg} / \mathrm{L}$ \\
BOD5 & Biochemical oxygen demand & $\mathrm{mg} / \mathrm{L}$ \\
$\mathrm{NH}_{3}-\mathrm{N}$ & Ammonia nitrogen & $\mathrm{mg} / \mathrm{L}$ \\
$\mathrm{TN}$ & Total nitrogen & $\mathrm{mg} / \mathrm{L}$ \\
$\mathrm{TP}$ & Total phosphorus & $\mathrm{mg} / \mathrm{L}$ \\
Petroleum & & $\mathrm{mg} / \mathrm{L}$ \\
FC & Petroleum & $\mathrm{pcs} / \mathrm{L}$
\end{tabular}


Table. 2 Descriptive statistics of water quality data from January 2011 to December 2019 in the PRE.

\begin{tabular}{|c|c|c|c|c|c|}
\hline & \multicolumn{5}{|c|}{ Pearl River Estuary } \\
\hline & Min & Max & Mean & Median & SD \\
\hline $\mathrm{COD}$ & 2.00 & 21.50 & 7.82 & 6.00 & 3.85 \\
\hline DO & 4.12 & 9.12 & 6.37 & 6.32 & 0.64 \\
\hline BOD5 & 0.70 & 4.30 & 1.49 & 1.30 & 0.51 \\
\hline $\mathrm{NH}_{3}-\mathrm{N}$ & 0.10 & 1.43 & 0.20 & 0.15 & 0.17 \\
\hline \multicolumn{6}{|l|}{ Water quality data } \\
\hline $\mathrm{TN}$ & 0.16 & 4.57 & 2.25 & 2.19 & 0.60 \\
\hline TP & 0.02 & 0.25 & 0.09 & 0.09 & 0.03 \\
\hline Petroleum & 0.005 & 0.14 & 0.03 & 0.02 & 0.02 \\
\hline $\mathrm{FC}$ & 32 & 18350.00 & 5392 & 4229 & 4241 \\
\hline EWQI & 17.66 & 114.16 & 50.68 & 49.17 & 17.38 \\
\hline
\end{tabular}

\section{Method}

\subsection{Entropy-based water quality index}

As an evaluation indicator of water quality, WQI is mainly related to a variety of environmental factors. Traditional WQI acquisition method usually adjusts the weight relationship between the parameters according to the empirical value, which could

156 cause the information loss ( Busico et al., 2020). In order to reduce the error caused by the inaccuracy of the weight of each input parameter, the information entropy is adopted 

the network structure of the information set, and realize to balance the distribution of various parameters with reasonable division. The larger of the entropy, the higher certainty of the event. The theory of entropy has been applied to water quality evaluation and other fields (Singh et.al., 2019). The main calculation steps as follows. $n)$. The matrix of $X$ can be rewritten as:

$$
X=\left[\begin{array}{cccc}
x_{11} & x_{12} & \ldots \ldots & x_{1 n} \\
x_{21} & x_{22} & \ldots . & x_{2 n} \\
\ldots & \ldots & & \ldots \\
x_{m 1} & x_{m 2} & \ldots . & x_{m n}
\end{array}\right]
$$

In order to eliminate the influence of different units and quality levels of each characteristic index. The feature indexes can be normalized with the Eq. (2).

$$
z_{i j}=\frac{x_{i j}-\left(x_{i j}\right)_{\min }}{\left(x_{i j}\right)_{\max }-\left(x_{i j}\right)_{\min }}
$$

The ratio of the index value with $j$ index and in $i$ sample can be calculated as:

$$
R_{i j}=z_{i j} / \sum_{i=1}^{m} y_{i j}
$$

The information entropy can be calculated with Eq. (4).

$$
E_{j}=-\frac{1}{\operatorname{Inm}} \sum_{i=1}^{m} R_{i j} \operatorname{In} R_{i j}
$$

Then, the entropy weight can be calculated according to the Eq. (5).

$$
W_{j}=\frac{1-E_{j}}{\sum_{j=1}^{n}\left(1-E_{j}\right)}
$$


Table. 3 The classification of water quality based on EWQI

\begin{tabular}{lll}
\hline EWQI & Grade & Water quality \\
\hline$<50$ & 1 & Excellent \\
$50-100$ & 2 & Good \\
$100-150$ & 3 & Medium \\
$150-200$ & 4 & Poor \\
$>200$ & 5 & Extremely poor \\
\hline
\end{tabular}

parameter. The $Q j$ which can be calculated with the following steps:

$$
Q_{j}=\frac{C_{j}}{S_{j}} \times 100
$$

Where $C j$ is the concentration of each environment factor in each water sample, and $S j$ is the limitation for water of each parameter according to the quality standards for water quality of China. Finally, the EWQI can be calculated according to the Eq. (7).

$$
E W Q I=\sum_{j=1}^{n} W_{j} Q_{j}
$$

Through the above calculation process, the actual value of EWQI can be obtained. In order to better understand the change of water quality, the international standard was introduced to realize the classification of water quality. The classification of water quality as shown in the Table 3. quality as shown in the Table 3 . 
generalized regression neural network (GRNN). The main logical relationship of the BP network structure is essentially a process of forward propagation of information and reverse correction of weights and thresholds based on errors. The original model usually needs to be corrected, while facing with some complex problems. The generalized regression neural network (GRNN) that proposed by the American scholar Specht in 1991 can well in dealing with this solution (Specht, 1991). It is a radial basis function (RBF) neural network based on the non-parametric kernel regression statistical method, and it is also a typical machine learning method (Bodyanskiy et.al., 2017). It is usually being used to solve the problems of function fitting and regression. It has many advantages such as strong nonlinear mapping ability and rapid learning speed while comparing with BP neural network.

The structure of GRNN mainly includes 4 layers: input layer, hidden layer, summation layer and output layer, which as shown in the Fig. 2. The number of model layer neurons is equal to the number of training set samples. The summation layer uses two types of neurons to represent the lines of all model layer neurons. One is unweighted, which represents the connection weight between the pattern layer and each neuron is equal to 1 . The second is to weight all the neurons in the pattern layer, and the connection weight is used as the output matrix of the training set. Each neuron of the output layer is associated with two types of results of the summation layer.

\subsubsection{Support vector machine method and optimization algorithm}

The support vector machine (SVM) method is based on the VC dimension of statistical learning theory and the principle of minimization of structural risk(Burges, 
1998; Cristianini and Shawe-Taylor, 2000;) SVM is similar to a multi-layer network structure perceptron and a radial basis function (RBF) network. The input vector is mapped into a high-dimensional feature space with a non-linear mapping which have been selected in advance, and the optimal classification hyperplane is constructed in this space. The main regression function as shown in Eq. (8)

$$
f(x)=w^{T} \cdot \varphi(x)+b
$$

$$
w^{\mathrm{T}} \cdot \varphi(x)+b
$$

Where $w$ is the weight vector, $b$ is the bias, and $\varphi(x)$ is a nonlinear mapping function.

The optimization process are as follows:

$$
\begin{gathered}
\min \frac{1}{2}\|w\|^{2}+C \sum_{i}^{n}\left(\xi+\xi_{i}^{*}\right) \\
\text { s.t. }\left\{\begin{array}{l}
y_{i}-w \cdot x_{i}-b \leq \varepsilon+\xi_{i} \\
w \cdot x_{i}+b-y \leq \varepsilon+\xi_{i}^{*} \\
\xi_{i}, \xi_{i}^{*} \geq 0
\end{array}\right.
\end{gathered}
$$

Where $\xi_{i}$ and $\xi_{i}^{*}$ are the slack variables, $C$ is the penalty parameter, $\varepsilon$ is the loss function parameter, as shown in Fig.3. The form of SVM for regression or classification model can be described as follows:

$$
f(x)=\sum_{i=1}^{n}\left(\alpha_{i}-\alpha_{i}^{*}\right) K\left(x_{i}, x\right)+b
$$

Where $K\left(x_{i}, x\right)$ is the kernel function, and the radial basis function (RBF) is usually used as the kernel function and its expression is presented as:

$$
K\left(x_{i}, x_{j}\right)=\exp \left(-\gamma\left\|x_{i}-x_{j}\right\|^{2}\right)
$$

230 Where $\gamma$ is the key parameter of RBF function.

\section{A. Particle swarm optimization (PSO)}


J, Eberhant R.C in 1995 (Kennedy et al, 1995). This algorithm is derived from the predation behavior of birds. During the process of predation, the location of the original food can be shared through the exchange of information. After obtaining the original location, the bird flock will center on it and scatter around to look for food sources, and finally realize simple and efficient predation.

The PSO algorithm randomly assigns an initial value to a feasible solution space population. Each particle of the population corresponds to a fitness value, which can judge the relative ability of an individual to transmit its own information to the next generation, and the characteristics can be represented by position and speed. Each particle can analyze the best position of surrounding particles and use the best position of particles in neighboring areas to adjust its own speed vector. The optimal particle will replace the most recent particle before the iteration. The fitness value will continuously adjust dynamically and optimal solution can be obtained.

\section{B. Artificial bee colony (ABC)}

Artificial bee colony algorithm was first proposed by Karaboga in 2005 (Karaboga et al, 2005). It is inspired by the behavior of bee colony for collecting honey. The mainly principle of the algorithm divides the bee colony into three types: collecting bee, observing bee, investigating bee. The task goal is to find the optimal nectar source which is the optimal solution of optimization problem. Each collecting bee corresponds to a certain nectar source (solution vector), and searches for nectar sources. According to the abundance of nectar sources (the size of the fitness value), roulette is used to hire 
observer bees to collect nectar (search for new nectar sources). If the nectar source is not improved after multiple updates, the nectar source is abandoned, and the collecting bee turns into a scout bee to randomly search for a new nectar source.

\section{Gray wolf optimization (GWO)}

Grey Wolf Optimizer (GWO) is a new meta-heuristic algorithm proposed by Mirjalili et al (Mirjalili et al, 1995), which refer to the social hierarchy and hunting behavior of gray wolves. The GWO algorithm simulates the social hierarchy and group hunting behavior of the gray wolf population, and realize the optimization of intelligent algorithm through the process of tracking, encircling, hunting, and attacking. This optimization algorithm adopts a new search mechanism, which only have few adjustment parameters, and it shows good performance while solving some optimization problems.

The optimization algorithm is based on the internal hierarchy of the gray wolf population, which can be divided into four parts: $\alpha, \beta, \delta$ and $\omega$. It has a strict pyramid hierarchy, $\alpha$ is the best solution, followed by $\beta$ and $\delta$, and the remaining solutions belong to $\omega$. The top 3 best wolves that are closest to their prey are $\alpha, \beta$, and $\delta$, which guide $\omega$ to search for prey in promising search areas. During the hunting process, the wolf will update its position around $\alpha, \beta$ and $\delta$, and determine the direction of optimization.

\section{Differential evolution and gray wolf optimization (DE-GWO)}

In order to update the diversity of the population, a differential algorithm which 
based on the global optimization is adopted. This method mainly generates a new population through the mechanism of mutation, crossover, and selection of population, and obtains the optimal solution. The GWO algorithm has demonstrated the superiority of its algorithm in many fields, but it is easy to fall into a local optimal solution while handling with some complex problem. The use of the difference algorithm to update the optimal position of the wolf pack can better prevent the GWO algorithm from falling into the local optimum.

\subsection{Model evaluation}

In order to effectively evaluate the performance of the optimization model that have used in this study, three commonly used evaluation indicators are adopted to describe the relationship between the actual value and the predicted value, which mainly include root mean squared error (RMSE), mean absolute percentage error (MAPE) and coefficient of correlation (R). RMSE is used to realize the measurement of deviation between the predicted value and the actual value, MAPE adopts the normalization method to avoid the influence of some noise points on the result, and it focuses on the process of comparing the predicted value with the actual value. The correlation coefficient $\mathrm{R}$ is used to evaluate how strong the relationship of the two variables. The calculation process of the evaluation indicators are as follows:

The RMSE can be calculated by referring to Eq. (12)

$$
R M S E=\sqrt{\frac{1}{m} \sum_{i=1}^{m}\left(E W Q I_{i}^{o}-E W Q I_{i}^{p}\right)^{2}}
$$




$$
M A P E=\frac{1}{m} \sum_{i=1}^{m}\left|\frac{E W Q I_{i}^{o}-E W Q I_{i}^{p}}{E W Q I_{i}^{o}}\right| \times 100
$$

The R can be calculated by referring to Eq. (14)

$$
R=\frac{\sum_{i=1}^{m}\left(E W Q I_{i}^{o}-\overline{E W Q I^{o}}\right)\left(E W Q I_{i}^{p}-\overline{E W Q I^{p}}\right)}{\sqrt{\sum_{i=1}^{m}\left(E W Q I_{i}^{o}-\overline{E W Q I^{o}}\right)^{2} \sum_{i=1}^{n}\left(E W Q I_{i}^{p}-\overline{E W Q I^{p}}\right)^{2}}}
$$

Where $x_{i}^{o}$ and $x_{i}^{p}$ are the actual and predicted value of EWQI at the month of $t, \overline{x^{o}}$ and $\overline{x^{p}}$ are the mean of the actual and predicted value of EWQI.

\section{Results and discussion}

\subsection{The analysis of relative environment factors}

The time series of water quality parameters were presented in the form of mean concentrations of all the sampling sites in Fig. 4 (the redlines reflect the level of the GB3838-2002 Class III standards). The variation of each parameter shows different characteristics without obvious change regularities. COD concentrations varied from 4.2 to $17.6 \mathrm{mg} / \mathrm{L}$, with an average of $7.82 \mathrm{mg} / \mathrm{L}$; DO concentrations varied from 5.17 to $7.92 \mathrm{mg} / \mathrm{L}$, with an average of $6.37 \mathrm{mg} / \mathrm{L}$; BOD5 concentrations varied from 0.88 to $2.68 \mathrm{mg} / \mathrm{L}$, with an average of $1.49 \mathrm{mg} / \mathrm{L} ; \mathrm{NH} 3-\mathrm{N}$ concentrations varied from 0.05 to $0.72 \mathrm{mg} / \mathrm{L}$, with an average of $0.20 \mathrm{mg} / \mathrm{L}$; TP concentrations varied from 0.05 to 0.19 $\mathrm{mg} / \mathrm{L}$, with an average of $0.09 \mathrm{mg} / \mathrm{L}$. According to china's environment quality standards for surface waters (GB3838-2002), COD and BOD5 can meet the Class I with a concentration limit of $15.0 \mathrm{mg} / \mathrm{L}$ and $3.0 \mathrm{mg} / \mathrm{L}$, respectively; DO and NH3-N can meet the Class II with a concentration limit of $6.0 \mathrm{mg} / \mathrm{L}$ and $0.5 \mathrm{mg} / \mathrm{L}$, respectively; TP can meet the Class III with a concentration limit of $0.2 \mathrm{mg} / \mathrm{L}$ and majority of it meets 
the Class II with a concentration limit of $0.1 \mathrm{mg} / \mathrm{L}$. From the first five parameters, little biochemical pollution and organic pollution were found in Nansha District waterways due to the increasingly stringent sewage discharge control policy. TN concentrations varied from 0.65 to $3.56 \mathrm{mg} / \mathrm{L}$, with an average of $2.25 \mathrm{mg} / \mathrm{L}$. TN often exceed Class III with a concentration limit of $1.0 \mathrm{mg} / \mathrm{L}$, which has been identified as the major pollution index that mainly caused by the fisheries, domestic pollution. Petroleum concentrations showed a significant falling trend and meet Class III with a concentration limit of $0.05 \mathrm{mg} / \mathrm{L}$ since July 2012. FC concentrations ranged from 283.4 to $14754.2 \mathrm{mg} / \mathrm{L}$ and has a slight increase trend. Most of the time, FC meet Class III with a concentration limit of $10 \mathrm{k}$ pcs/L. factors and EWQI

\begin{tabular}{ccccccccc}
\hline Variables & COD & DO & BOD5 & NH3N & TN & TP & Petroleum & FC \\
\hline Correction (r) & 0.32 & -0.18 & 0.19 & 0.36 & 0.03 & 0.32 & 0.76 & 0.40 \\
\hline
\end{tabular}

According to the results of Table 4, the correlation between the different environmental factors and the EWQI are not the same. It can be found that petroleum 
is most related to EWQI, and DO show negative correlation with EWQI. We divide the

342 input environmental factors into three categories by referring the standard evaluation

343 as shown in the Table 5. Three different combinations of the input environmental factors

344 are act as the input vectors for the optimization model, which as shown in the Table 6.

345 Table. 5 The standard evaluation of Pearson correlation coefficient

\begin{tabular}{ccccc}
\hline Correction (r) & $|\mathrm{r}| \geq 0.8$ & $0.8>|\mathrm{r}|$ & $0.5>|\mathrm{r}|$ & $0.3>|\mathrm{r}|$ \\
& & $\geq 0.5$ & $\geq 0.3$ & \\
\hline Degree of correlation & High & Medium & Low & No \\
\hline
\end{tabular}

Table. 6 Different combination of input environment factors

\begin{tabular}{ll}
\hline No & Different input combination \\
\hline 1 & Petroleum \\
2 & Petroleum, FC, $\mathrm{NH}_{3}-\mathrm{N}, \mathrm{COD}, \mathrm{TP}$ \\
3 & Petroleum, FC, NH3N, COD, TP, BOD5, DO, TN \\
\hline
\end{tabular}

In order to select best combination of environmental factors to achieve high accuracy prediction, RMSE is used to evaluate the performance of GRNN and SVM. The results as shown in the Table 7.

Table. 7 The results of RMSE with different combinations of environmental factors

\begin{tabular}{ccccc}
\hline \multirow{2}{*}{ Prediction } & \multicolumn{4}{c}{ RMSE } \\
\cline { 2 - 5 } model & Phase & 1 & 2 & 3 \\
\hline GRNN & Training & 11.03 & 2.76 & 2.34
\end{tabular}




\begin{tabular}{ccccc} 
& Testing & 12.35 & 7.30 & 8.76 \\
\hline \multirow{2}{*}{ SVM } & Training & 11.12 & 1.18 & 0.66 \\
& Testing & 13.14 & 4.63 & 6.19 \\
\hline
\end{tabular}

As it can be known from the Table 7, both GRNN and SVM can achieve high prediction accuracy in the training phase, and the accuracy of SVM is better than GRNN in the testing phase. Meanwhile, the RMSE is quite different with using different combinations of environmental factors, which show that different environment factors combination is selected as the new input vectors for the optimization model. lower than the other three algorithms. However, four hybrid algorithms can all achieve 
DE-GWO-SVM algorithm is higher than that of GWO-SVM in the training phase, but

373 show no more obvious advantages over GWO-SVM in the testing phase. According to

374 the value of RMSE and MAPE, DE-GWO-SVM show obvious advantages than the

375 other three optimization algorithms not only in the training phase but also in the testing 376 phase.

377 Table. 8 The results of three different evaluation indicators with using different 378 optimization algorithms

\begin{tabular}{lllll}
\hline & Phase & RMSE & MAPE & R \\
\hline \multirow{2}{*}{ PSO } & Training & 0.9806 & 1.9495 & 0.9984 \\
& Testing & 2.5332 & 3.2056 & 0.9905 \\
\hline ABC & Training & 1.4929 & 2.6229 & 0.9963 \\
& Testing & 3.6317 & 3.5007 & 0.9813 \\
\hline GWO & Training & 1.0828 & 2.0439 & 0.9981 \\
& Testing & 2.2363 & 3.0706 & 0.9928 \\
\hline & Training & 0.8673 & 1.4417 & 0.9988 \\
\hline
\end{tabular}

In order to directly characterize the deviation between the predicted value and the actual value, we make a detailed comparative analysis as shown in Fig. 6. The predicted value and the actual value are basically fluctuated on the same line. However, while the

383 value of EWQI is too large, the accuracy of the four algorithms are not consistent. We 
obvious exist with using ABC-SVM, and PSO-SVM. Only the results of GMO-SVM and DE-GMO-SVM keep consistent. The deviation of some salient points indicates that the optimization algorithm may falls into local optimization in some aspects and cannot achieve global optimization. This also prove that GWO or DE-GWO optimization algorithm have better performance while facing with some complex situation. The DE algorithm which can be used to further improve the performance of the prediction model and avoid falling into local optimal solutions.

\subsection{Comparative analysis of the application of different optimization SVM models}

\section{in nonlinear regression classification}

As a supervised learning model, SVM show outstanding characteristics while dealing with nonlinear regression prediction and classification problem based on small samples. Different optimization algorithms have been used to realize the nonlinear regression prediction in Section 4.3. However, more attention is focused on the evaluation of water quality grade with using the most relevant environment factors.

According to the best combination of environment factors what have selected in the section 4.2, the value of EWQIs are being labeled to different grade to represent the water quality levels. The evaluation indicator that have mentioned in section 3.3 mainly not applicable to evaluate the water quality levels, and the accuracy rate is adopted to evaluate the different hybrid optimization algorithms. The results of accuracy rate as shown in the Table 9.

Table. 9 The accuracy rate of four different optimization algorithms in evaluating the 
water quality level.

\begin{tabular}{lll}
\hline & Training & Testing \\
Prediction model & & \\
\hline PSO-SVM & $94.71 \%$ & $88.96 \%$ \\
ABC-SVM & $94.97 \%$ & $87.73 \%$ \\
GWO-SVM & $97.09 \%$ & $92.02 \%$ \\
DE-GWO-SVM & $97.88 \%$ & $95.09 \%$ \\
\hline
\end{tabular}

From the results of the table 9 , it can be seen that the four different optimization algorithms can achieve high accuracy in the training phase, and the prediction accuracy of GWO and DE-GWO is more than $97 \%$. In the testing phase, the prediction accuracy of the optimization model tends to decrease. Among them, the prediction accuracy of ABC-SVM is greatly reduced, and its prediction accuracy is only $87.73 \%$, which is not suitable for the practical applications. However, the accuracy rate of DE-GWO-SVM reaches $95.09 \%$ in the testing phase, which can meet the actual application requirements.

\section{Conclusion}

The monitoring of water quality in estuaries has always attracted more attention. This is not only related to water security, but also related to the sustainable development of water resources management. Complex and comprehensive physical models are usually being used to evaluate the water quality. These models are challenging to construct, characterize, and calibrate. In addition, these models rely more on collecting datasets which are expensive and time-consuming. 
This paper focuses on using efficient machine learning methods to realize the evaluation of water quality. The method of Pearson is used to realized the division of environment factors. While comparing the performance of ANN and SVM, the best combination of environmental factors can be selected. Since the model of SVM show higher accuracy in predicting the EWQI, and four optimization algorithms are used to optimize the SVM to further improve the prediction accuracy of EWQI and water quality grade classification. At last, the model of DE-GWO-SVM show great potential to realize the prediction of EWQI and water quality grade. The research in this article shows that machine learning has obvious advantages in water quality prediction, but it is still necessary to continuously study the adaptability of different models to different research areas. High-efficiency and accurate machine learning models are still the trend of future research.

Authors Contribution All authors contributed to the conception and design of the study. J. J. Xia mainly responsible for data processing and model establishment, and J. Zeng mainly responsible for result analysis and paper writing. All authors read and approved the final manuscript.

Funding The supports of this work by the Natural Science Foundation of Hubei Province (2020CFB292).

Availability of Data and Material The datasets used and/or analyzed during the current study are available from the corresponding author on reasonable request.

Code Availability The code used during the current study are available from the 
corresponding author on reasonable request.

\section{Declarations}

Ethics Approval There are no relevant waivers or approvals.

Consent to Participate Authors consent to their participation in the entire review process.

Consent for Publication Authors allow publication if the research is accepted.

Competing Interests The authors declare that they have no known competing financial interests or personal relationships that could have appeared to influence the work reported in this paper.

\section{Reference}

Ahsan, W.A., Ahmad, H.R., Farooqi, Z.U.R., Sabir, M., Ayub, M.A., Rizwan, M., Ilic, P., 2021. Surface water quality assessment of Skardu springs using Water Quality Index. Environmental Science and Pollution Research 28, 20537-20548. https://doi.org/10.1007/s11356-020-11818-5

Ameen, H.A., 2019. Spring water quality assessment using water quality index in villages of Barwari Bala, Duhok, Kurdistan Region, Iraq. Applied Water Science 9, 1-12. https://doi.org/10.1007/s13201-019-1080-z

Busico, G., Kazakis, N., Cuoco, E., Colombani, N., Tedesco, D., Voudouris, K., Mastrocicco, M.,2020. A novel hybrid method of specific vulnerability to anthropogenic pollution using multivariate statistical and regression analyses. Water Res. 171, 115386.

Chrostorpher. J.C. Burges (1998) A Tutorial on Support Vector Machines for Pattern Recognition. Data Mining and Knowledge Discovery 2:121-167

Cristianini N, Shawe-Taylor J (2000) An Introduction to Support Vector Machines 
and Other Kernel-Based Learning Methods.

D. F. Specht, 'A general regression neural network'. IEEE Press, Nov. 01, 1991, Accessed: Apr. 10, 2020. [Online]. Available: https://doi.org/10.1109/72.97934.

Dhanasekarapandian, M., Chandran, S., Devi, D.S., Kumar, V., 2016. Spatial and temporal variation of groundwater quality and its suitability for irrigation and drinking purpose using GIS and WQI in an urban fringe. Journal of African Earth Sciences 124, 270-288. https://doi.org/10.1016/j.jafrearsci.2016.08.015

E. R. Kennedy J (1995), Particle swarm optimisation, IEEE Int. Conf. Neural Networks, Perth,Australia, pp. 1942-1948.

Feng, Y., Fanghui, Y., Li, C., 2019. Improved Entropy Weighting Model in Water Quality Evaluation. Water Resources Management 33, 2049-2056. https://doi.org/10.1007/s11269-019-02227-6

Gao, Y., Qian, H., Ren, W., Wang, H., Liu, F., Yang, F., 2020. Hydrogeochemical characterization and quality assessment of groundwater based on integratedweight water quality index in a concentrated urban area. Journal of Cleaner Production 260, 121006. https://doi.org/10.1016/j.jclepro.2020.121006.

Gupta, R., Singh, A.N., Singhal, A., 2019. Application of ANN for water quality index. International Journal of Machine Learning and Computing 9 (5), 688e693.

Hamzeh Haghibi, A., Nasrolahi, A., Parsaie, A., 2018. Water quality prediction using machine learning methods. Water Quality Research Journal 53 (1), 3-13.

Hou, W., Sun, S., Wang, M., Li, X., Zhang, N., Xin, X., Sun, L., Li, W., Jia, R., 2016. Assessing water quality of five typical reservoirs in lower reaches of Yellow River, China: Using a water quality index method. Ecological Indicators 61, 309-316. https://doi.org/10.1016/j.ecolind.2015.09.030

Kaurish, F.W., Younos, T., 2007. Developing a standardized water quality index for evaluating surface water quality. Journal of the American Water Resources Association 43, 533-545. https://doi.org/10.1111/j.1752-1688.2007.00042.x

Karaboga D, An idea based on honey bee swarm for numerical optimization, Tech. Report. TR06, Erciyes Univ. Press., 2005.

Li, S., Chen, X., Singh, V.P., He, Y., Bai, X., 2019. An improved index for water 

quality evaluation in an estuary region: A case study in the Eastern Pearl River Delta, China. Water Policy 21, 310-325. https://doi.org/10.2166/wp.2019.151

Machiwal, D., Cloutier, V., Güler, C., Kazakis, N., 2018. A review of GIS-integrated statistical techniques for groundwater quality evaluation and protection. Environmental Earth Science 77, 681.

Nong, X., Shao, D., Zhong, H., Liang, J., 2020. Evaluation of water quality in the South-to-North Water Diversion Project of China using the water quality index (WQI) method. Water Research 178, 115781. https://doi.org/10.1016/j.watres.2020.115781

Nukapothula, S., Chen, C., Wu, J., 2019. Long-term distribution patterns of remotely sensed water quality variables in Pearl River Delta, China. Estuarine, Coastal and Shelf Science 221, 90-103. https://doi.org/10.1016/j.ecss.2019.02.038

Rajaee, T., Khani, S., Ravansalar, M., 2020. Artificial intelligence-based single and hybrid models for prediction of water quality in rivers: A review. Chemometrics and Intelligent Laboratory Systems 200, 103978. https://doi.org/10.1016/j.chemolab.2020.103978

Sakizadeh, M., 2016. Artificial intelligence for the prediction of water quality index in groundwater systems. Modeling Earth Systems and Environment 2 (1), 8. https://doi.org/10.1007/s40808015-0063-9.

Seifi, A., Dehghani, M., Singh, V.P., 2020. Uncertainty analysis of water quality index (WQI) for groundwater quality evaluation: Application of Monte-Carlo method for weight allocation. Ecological Indicators 117, 106653. https://doi.org/10.1016/j.ecolind.2020.106653

Singha, S., Pasupuleti, S., Singha, S.S., Singh, R., Kumar, S., 2021. Prediction of groundwater quality using efficient machine learning technique. Chemosphere 276, 130265. https://doi.org/10.1016/j.chemosphere.2021.130265

Singh, K.R., Dutta, R., Kalamdhad, A.S., Kumar, B., 2019. Information entropy as a tool in surface water quality assessment. Environmental Earth Sciences 78 (1), 15.

S. Mirjalili, S. M. Mirjalili, and A. Lewis (2014), “Grey Wolf Optimizer,” Adv. Eng. 
Softw., 69.

SudhakarSingha., 2021, Prediction of groundwater quality using efficient machine learning technique. Chemosphere,Volume 276, August 2021, 130265

Sutadian, A.D., Muttil, N., Yilmaz, A.G., Perera, B.J.C., 2017. Using the Analytic Hierarchy Process to identify parameter weights for developing a water quality index. Ecological Indicators 75, 220-233. https://doi.org/10.1016/j.ecolind.2016.12.043

Tian, Y., Jiang, Y., Liu, Q., Dong, M., Xu, D., Liu, Y., Xu, X., 2019. Using a water quality index to assess the water quality of the upper and middle streams of the Luanhe River, northern China. Science of the Total Environment 667, 142-151. https://doi.org/10.1016/j.scitotenv.2019.02.356

van Vliet, M.T.H., Jones, E.R., Flörke, M., Franssen, W.H.P., Hanasaki, N., Wada, Y., Yearsley, J.R., 2021. Global water scarcity including surface water quality and expansions of clean water technologies. Environmental Research Letters 16. https://doi.org/10.1088/1748-9326/abbfc3

Wang, X., Zhang, F., Ding, J., 2017. Evaluation of water quality based on a machine learning algorithm and water quality index for the Ebinur Lake Watershed,China. Sci. Rep. 7 (1), 1e18. https://doi.org/10.1038/s41598-017-12853-y.

Wu, H., Yang, W., Yao, R., Zhao, Yue, Zhao, Yunqiang, Zhang, Y., Yuan, Q., Lin, A., 2020. Evaluating surface water quality using water quality index in Beiyun River, China. Environmental Science and Pollution Research 27, 35449-35458. https://doi.org/10.1007/s11356-020-09682-4

Wu, Z., Wang, X., Chen, Y., Cai, Y., Deng, J., 2018. Assessing river water quality using water quality index in Lake Taihu Basin, China. Science of the Total Environment 612, 914-922. https://doi.org/10.1016/j.scitotenv.2017.08.293

Xia, J., Xu, G., Guo, P., Peng, H., Zhang, X., Wang, Y., Zhang, W., 2018. TempoSpatial Analysis of Water Quality in the Three Gorges Reservoir, China, after its 175-m Experimental Impoundment. Water Resources Management. https://doi.org/10.1007/s11269-018-1918-4

Xiao, J., Wang, L., Deng, L., Jin, Z., 2019. Characteristics, sources, water quality and 

health risk assessment of trace elements in river water and well water in the Chinese Loess Plateau. Science of the Total Environment 650, 2004-2012. https://doi.org/10.1016/j.scitotenv.2018.09.322

Yang, K., Yu, Z., Luo, Y., Yang, Y., Zhao, L., Zhou, X., 2018. Spatial and temporal variations in the relationship between lake water surface temperatures and water quality - A case study of Dianchi Lake. Science of the Total Environment 624, 859-871. https://doi.org/10.1016/j.scitotenv.2017.12.119

Ye. V. Bodyanskiy, A. O. Deineko, and Ya. V. Kutsenko, 'On-line kernel clustering based on the general regression neural network and T. Kohonen's self-organizing map', Aut. Control Comp. Sci., vol. 51, no. 1, pp. 55-62, Jan. 2017, doi: $10.3103 / \mathrm{S} 0146411617010023$

Zahedi, S., Azarnivand, A., Chitsaz, N., 2017. Groundwater quality classification derivation using Multi-Criteria-Decision-Making techniques. Ecological Indicators 78, 243-252. https://doi.org/10.1016/j.ecolind.2017.03.015 
Figures

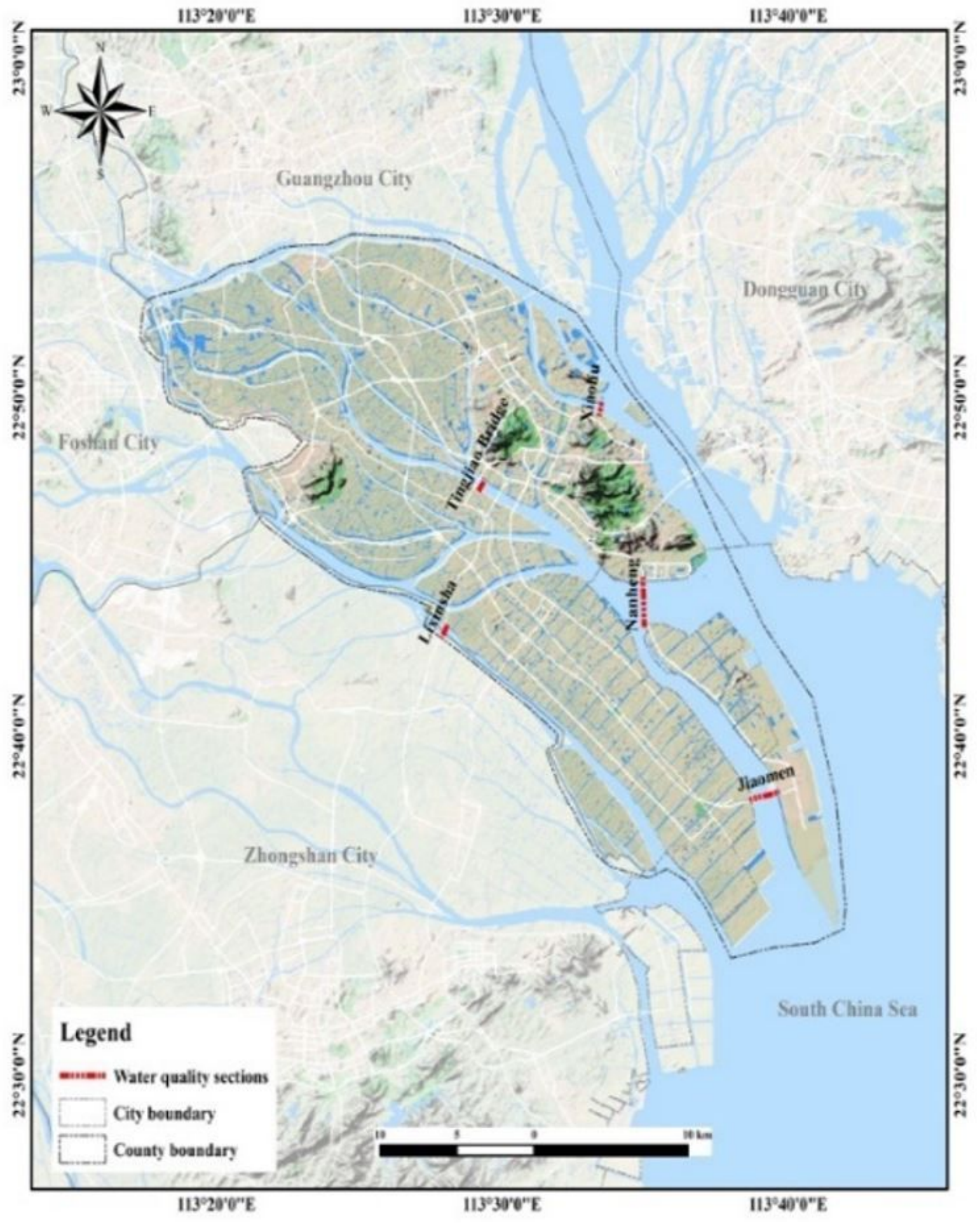

Figure 1

The location of the PRE and distribution of the monitoring station. 


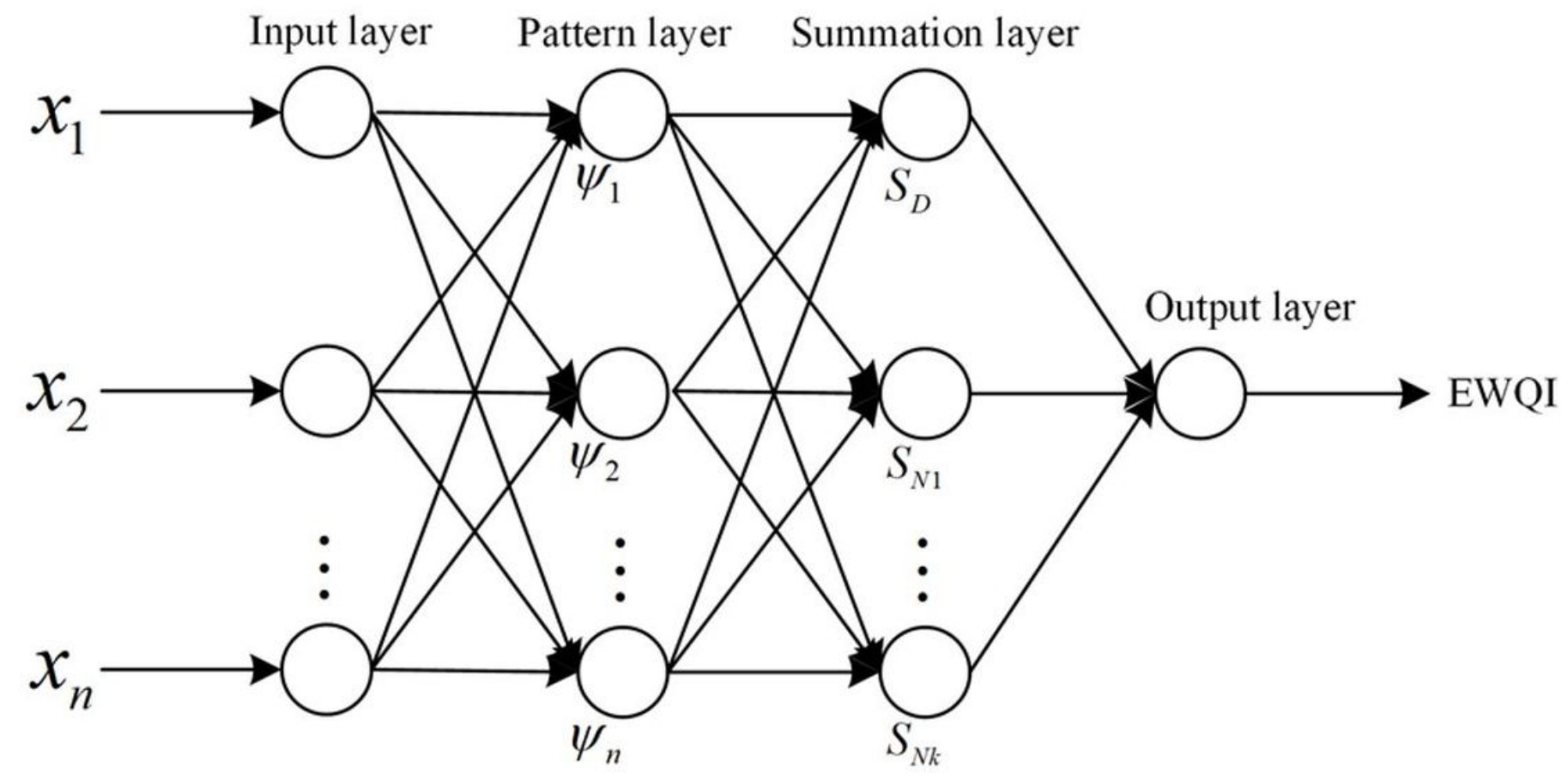

Figure 2

The basic network structure of GRNN 


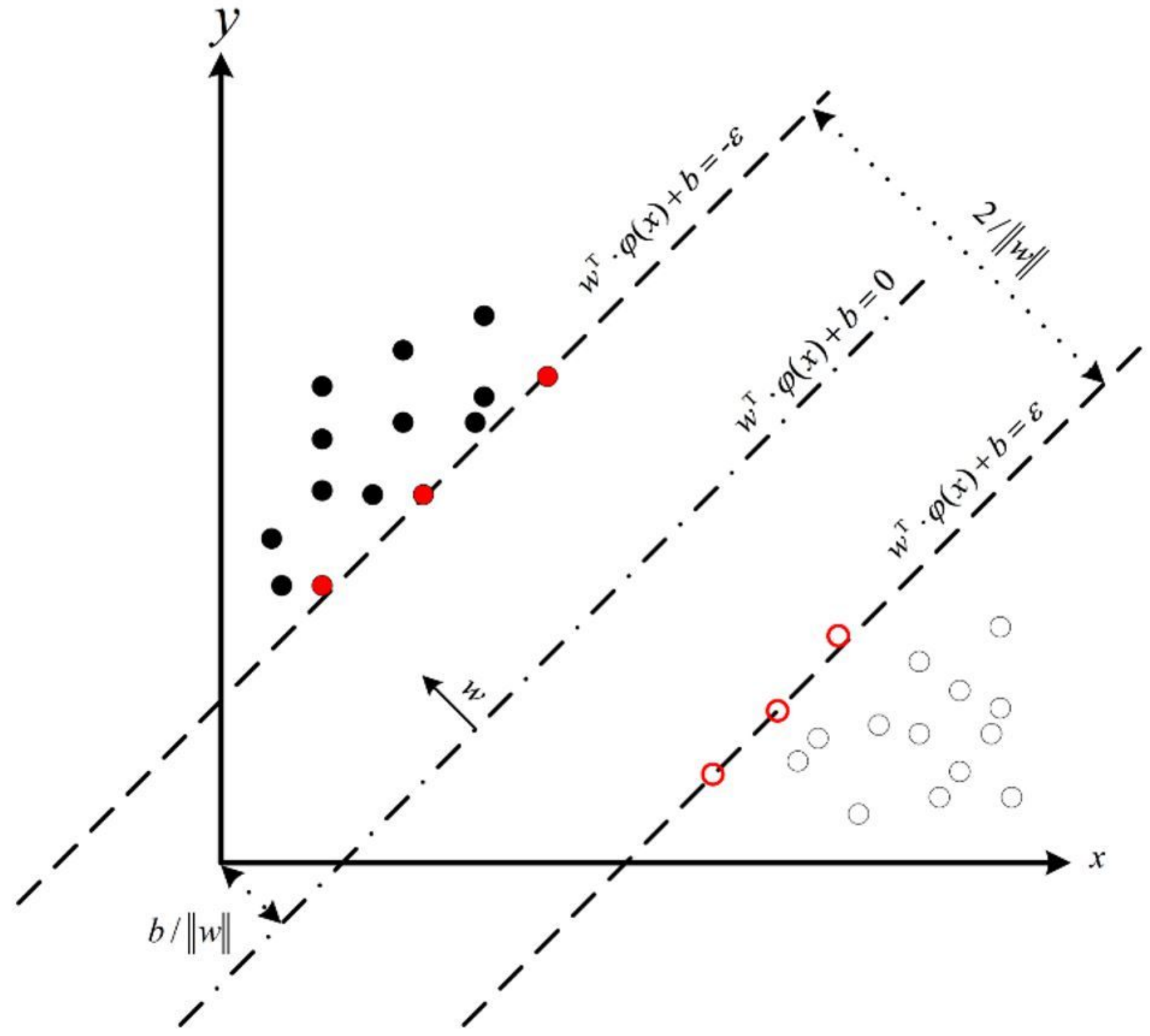

Figure 3

The simple structure of SVM 

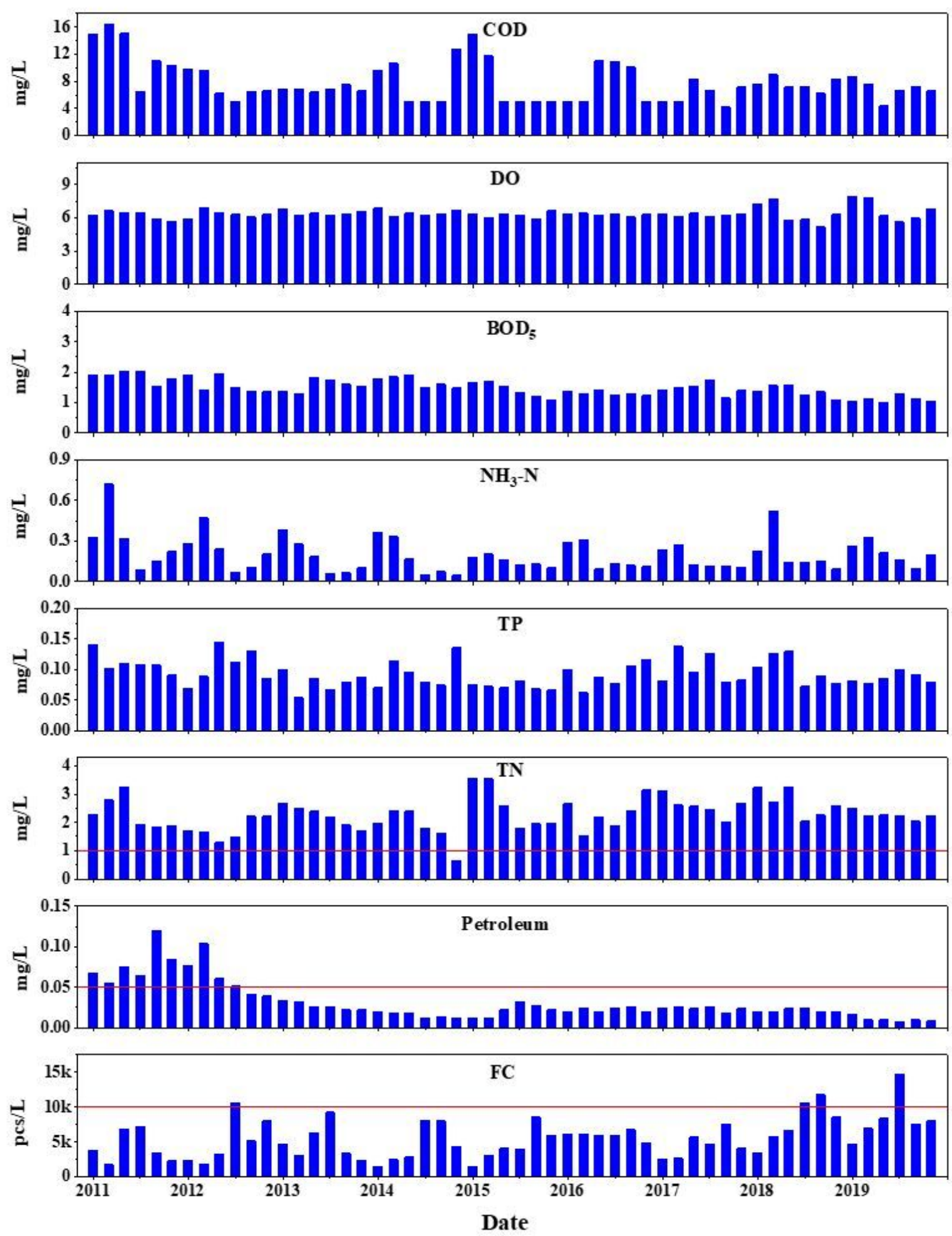

Figure 4

Water quality variables time series in Nansha District waterways from 2011 to 2019. 


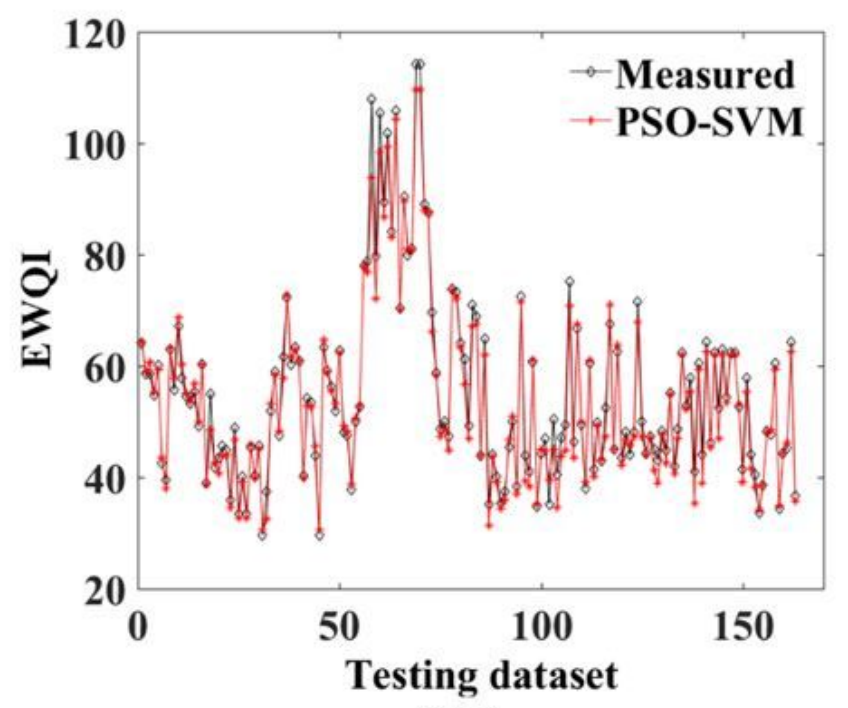

(A)

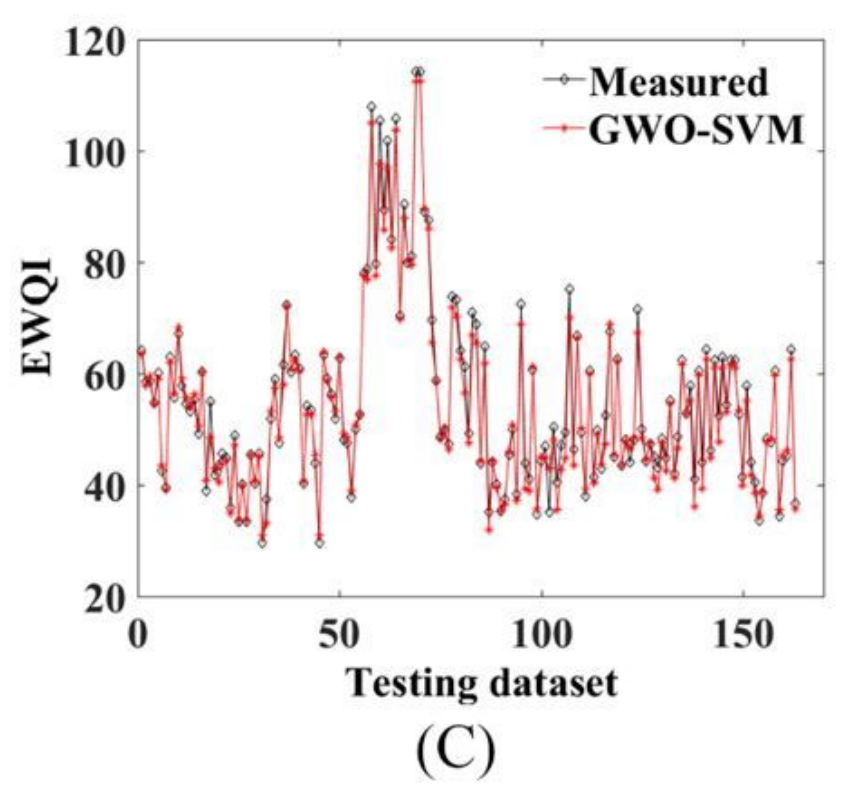

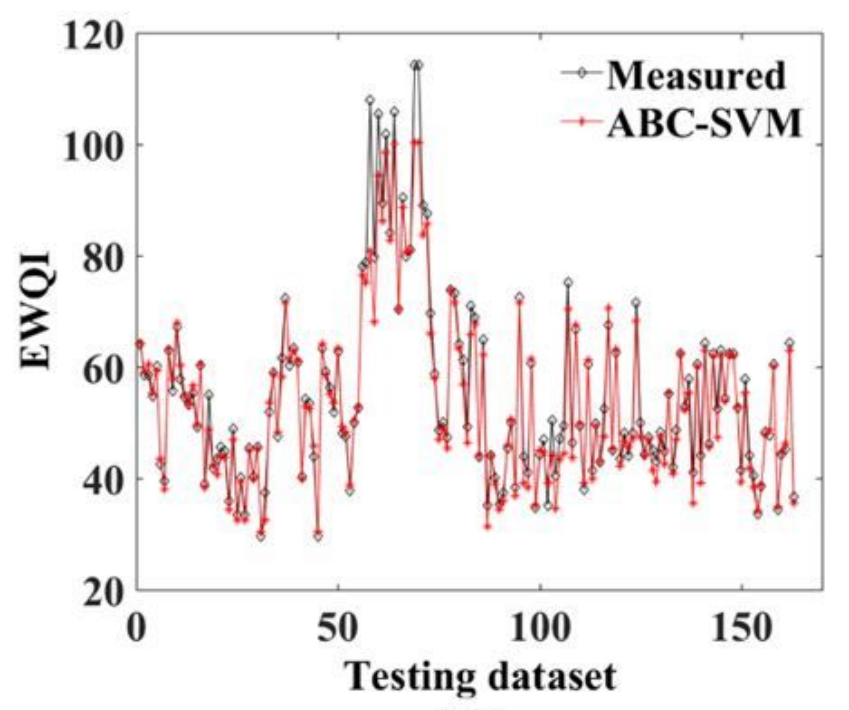

(B)

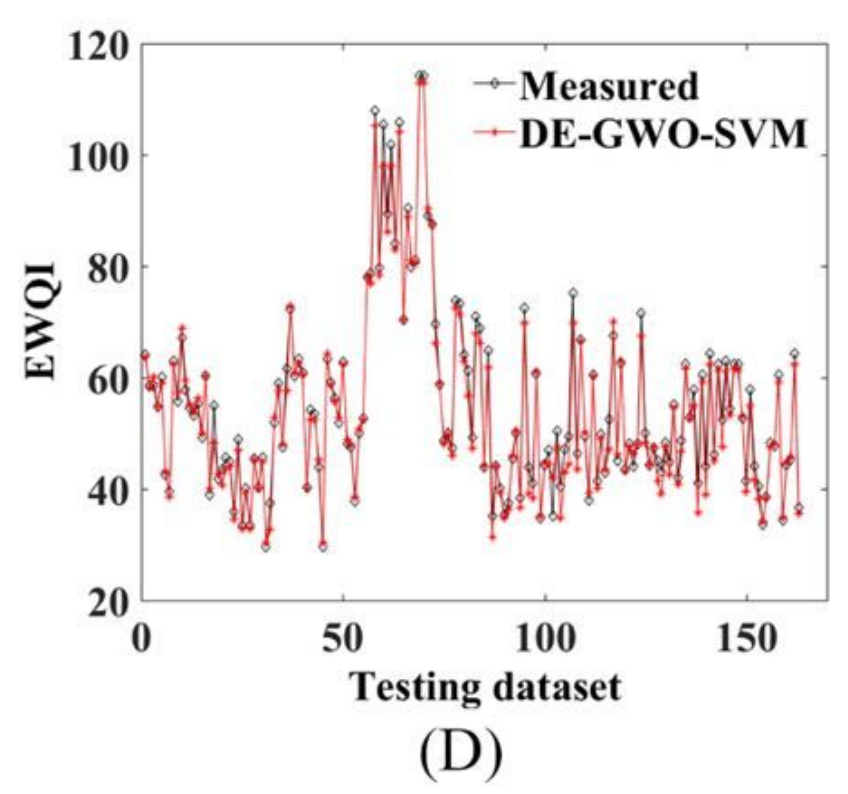

Figure 5

The prediction results of four optimization algorithms in the testing phase 


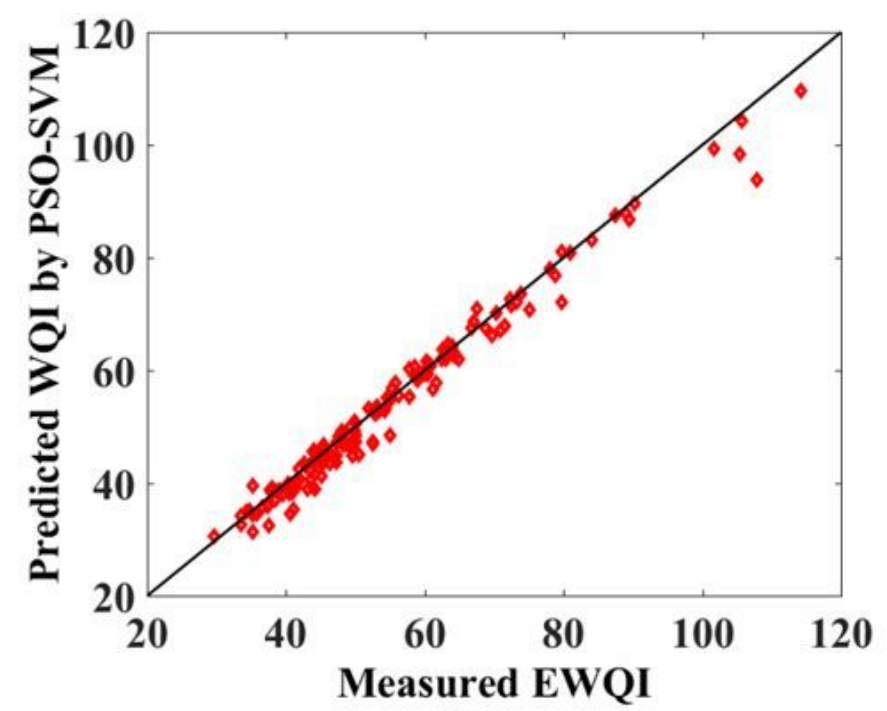

(A)

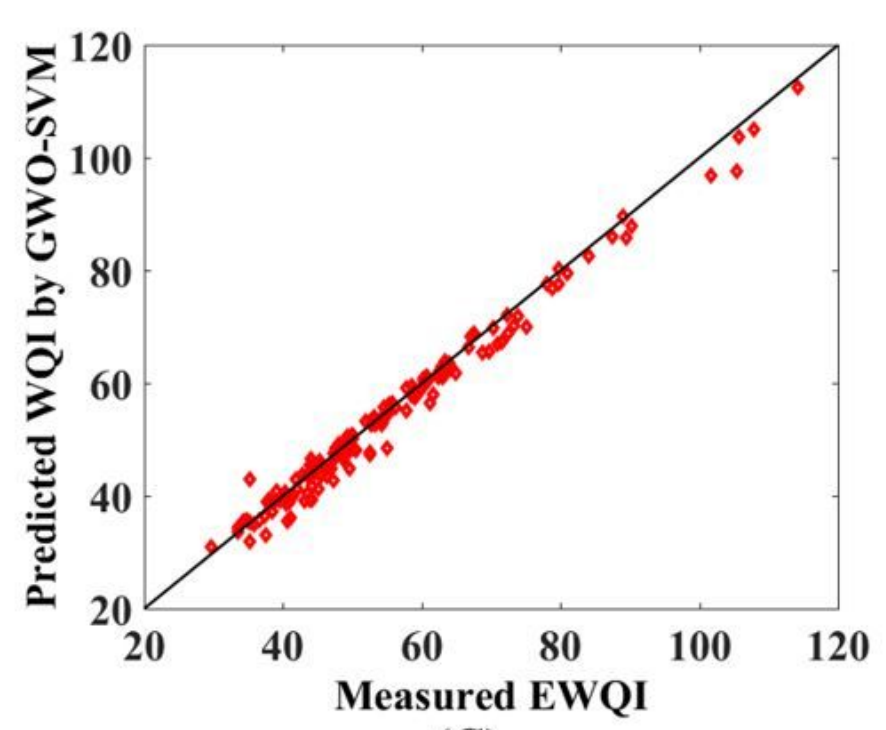

(C)

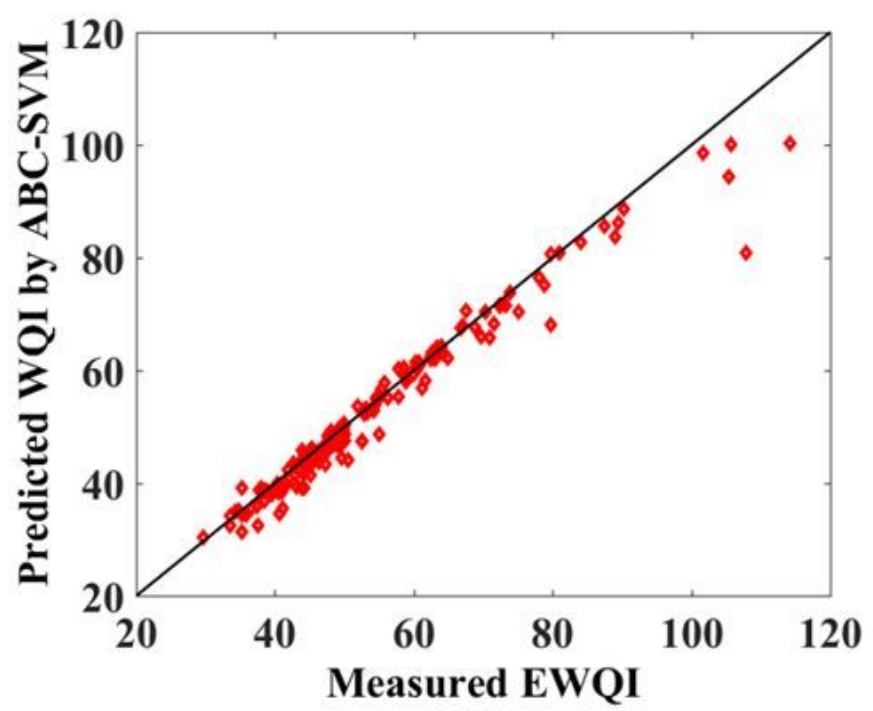

(B)

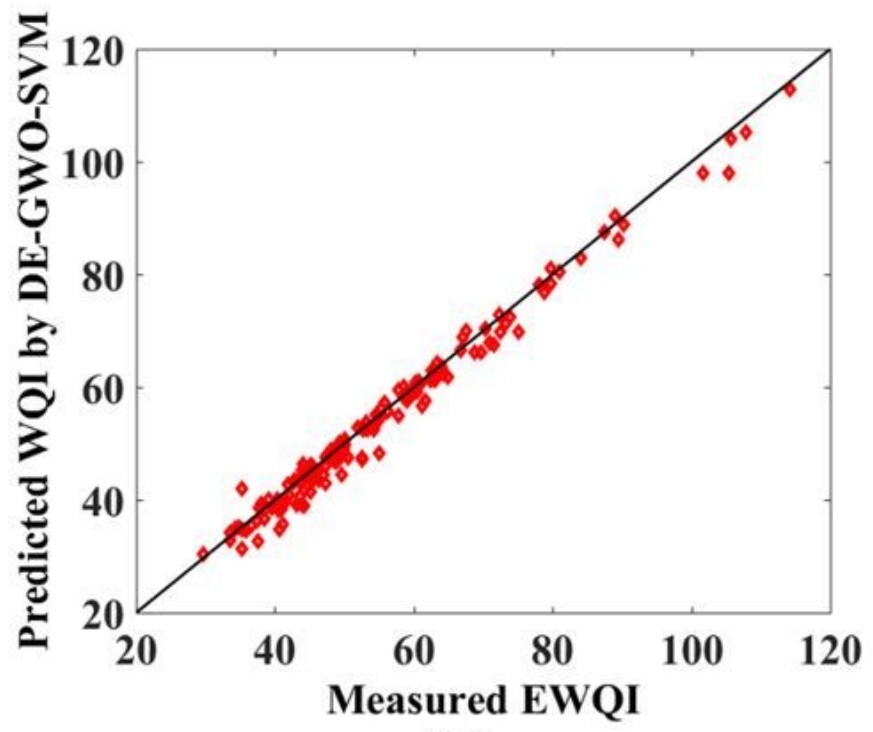

(D)

Figure 6

The predicted value VS actual value with using four optimization algorithms. 